\title{
DNA Damage and Apoptosis in Alzheimer's Disease: Colocalization with C-Jun Immunoreactivity, Relationship to Brain Area, and Effect of Postmortem Delay
}

\author{
Aileen J. Anderson, Joseph H. Su, and Carl W. Cotman \\ Institute for Brain Aging and Dementia, University of California, Irvine, California 92717-4550
}

\begin{abstract}
Many neurons in Alzheimer's disease (AD) exhibit terminal deoxynucleotidyl transferase (TdT) labeling for DNA strand breaks with a distribution suggestive of apoptosis. We have shown previously that immunoreactivity for c-Jun is elevated in $A D$ and found in association with neuronal pathology. In addition, cultured neurons undergoing $\beta$-amyloid-mediated apoptosis exhibit a selective and prolonged induction of c-Jun. Consequently, we conducted double-labeling experiments to examine whether c-Jun is associated with DNA strand breaks in $A D$ tissue; we observed a strong colocalization between these markers. As would be predicted based on the distribution of $A D$ pathology, we also found that TdT labeling was prominent in the entorhinal cortex, but absent or at very low levels in cerebellum. Furthermore, we confirmed that postmortem delay (PMD) does not affect TdT labeling within the limits used for tissue used in this study. However, in contrast to previous
\end{abstract}

studies, we report an increase in TdT labeling with more extended PMDs. Finally, gel electrophoresis of genomic DNA isolated from $A D$ and control cases failed to reveal evidence for either an apoptotic or a necrotic mechanism of cell death in $A D$, possibly because of a low number of cells actually undergoing cell death at any given time. Our findings support the hypothesis that DNA damage labeled using TdT reflects neuronal vulnerability and cell loss associated with AD pathology, and that at least a portion of the cells labeled with this technique is undergoing apoptosis. Furthermore, in agreement with in vitro findings, these results suggest a relationship between the expression of c-Jun and neuronal risk and/or cell death in AD.

Key words: immediate early gene; proto-oncogene; immunocytochemistry; neurodegeneration; cell death; DNA fragmentation; gel electrophoresis; terminal deoxynucleotidyl transferase; cerebellum; entorhinal cortex
Apoptosis has been suggested to play a protective role in disease by minimizing insult to surrounding cells and tissues attributable to inflammation (Bursch et al., 1992). Conversely, we have suggested that apoptosis may participate in the disease state, as a part of the cascade of events resulting from a neurodegenerationinducing stimulus (Loo ct al., 1993; Su ct al., 1994). Apoptosis is dependent on the activation of a gene program for cell death in some systems. The expression of the immediate early gene (IEG) c-jun has been associated with apoptosis both in vitro (Bhalla et al., 1992; Brach et al., 1992; Rubin et al., 1992; Bullock et al., 1993; Sikora et al., 1993) and in vivo (Dragunow et al., 1994; Marti et al., 1994), and a direct relationship between c-Jun expression and apoptotic cell death has been identified in both non-neuronal and neuronal models (Colotta et al., 1992; Estus et al., 1994; Ham et al., 1995).

Apoptosis is characterized by the degradation of nuclear DNA in many, but not all, models of apoptosis (Duke et al., 1983; Wyllie et al., 1984; Tepper and Studzinski, 1992; Zakeri et al., 1993). The

\footnotetext{
Received Dec. 4, 1995; accepted Dec. 6, 1995.

This work was supported by National Institutes of Health Grants AG13007, AG05142, and AG07918 to C.W.C. We thank Dr. Brian J. Cummings, director of the Institute for Brain Aging and Dementia Tissue Repository, for consultations and helpful discussions. We also acknowledge the Kathleen Price Bryan Brain Bank and the Alzheimer's Disease Research Center at Duke University for providing rapid autopsy tissue P50 AG05128.

Correspondence should be addressed to Aileen J. Anderson, Institute for Brain Aging and Dementia, 1305 Biological Sciences II, University of California, Irvine, CA $92717-4550$.

Dr. Anderson's present address: Laboratories for Molecular Neuroscience, Harvard Medical School, Department of Psychiatry, Mailman Research Center, McLean Hospital, 115 Mill Street, Belmont, MA 02178-9106.

Copyright (C) 1996 Society for Neuroscience $0270-6474 / 96 / 161710-10 \$ 05.00 / 0$
}

process of DNA degradation in apoptosis produces a series of oligonucleosome-length DNA fragments that have newly generated 3'-OH ends. Conversely, normal cells have very low numbers of terminal DNA strand breaks. DNA fragmentation labeling techniques use enzymes such as terminal deoxynucleotidyl transferase (TdT) or Klenow polymerase to catalyze the addition of deoxynucleotide triphosphates to the $3^{\prime}-\mathrm{OH}$ termini of single- or double-stranded DNA, which can then be visualized immunohistochemically. We have reported recently that cells in the $\mathrm{Alz}$ heimer's disease (AD) brain exhibit labeling for DNA strand breaks using TdT, and that at the light microscopy level the morphological distribution of this labeling in many cells is consistent with apoptosis (Su et al., 1994). To understand the mechanisms of neuronal degeneration in $\mathrm{AD}$, it will be necessary to extend these studies to examine multiple cell death pathway markers.

Cultured neurons exposed to $\beta$-amyloid $(\mathrm{A} \beta)$ peptides undergo apoptotic cell death (Forloni et al., 1993; Loo et al., 1993). We have reported that neurons that initiate apoptosis in this paradigm also exhibit a selective and prolonged expression of c-Jun, and that neurons resistant to $\mathrm{A} \beta$-induced apoptosis do not express c-Jun in this model (Anderson et al., 1995). Furthermore, c-Jun is selectively induced in neurons undergoing apoptosis but not necrosis both in culture (Anderson et al., 1995) and in response to hypoxic-ischemic injury in rat brain (Dragunow et al., 1994). Consequently, we have suggested that c-Jun participates in an apoptotic program for cell death in $A \beta$-treated neurons. In parallel with these results, we have reported increases in immunoreactivity for c-Jun in AD compared with control cases, and the 
colocalization of immunoreactivity for c-Jun with neuronal pathology in AD (Anderson et al., 1994).

In the present study, we examined the colocalization of immunoreactivity for c-Jun with TdT labeling in AD tissue to evaluate the hypothesis that TdT-labeled nuclei may have initiated a genemediated program of apoptotic cell death involving c-Jun. To further evaluate TdT labeling and the mechanism of cell death in $\mathrm{AD}$, we also examined the distribution of TdT labeling across brain area, the effect of postmortem delay (PMD) on TdT labeling, and genomic DNA isolated from both control and $\mathrm{AD}$ tissue.

\section{MATERIALS AND METHODS}

Human tissue. The entorhinal cortex from eight $\mathrm{AD}$ and six control cases was examined. Fresh brain tissue was fixed in $10 \%$ formalin in $0.1 \mathrm{M}$ Sorensen's buffer, $\mathrm{pH} 7.3$, for $48-72 \mathrm{hr}$ and stored in $0.1 \mathrm{M}$ PBS $(0.02 \%$ sodium azide) at $4^{\circ} \mathrm{C}$. All experiments used free-floating $50 \mu \mathrm{m}$ sections cut on a Vibratome (Technical Products International, St. Louis, MO) and collected in PBS, pH 7.4. AD tissue was taken from neuropathologically defined cases that met the Consortium to Establish a Registry for the Diagnosis of Alzheimer's Disease (CERAD) requirements (Mirra et al., 1991). Both conventional postmortem tissue (obtained from the Institute for Brain Aging and Dementia Tissue Repository) and rapid autopsy tissue (obtained from the Kathleen Price Bryan Brain Bank and the Alzheimer's Disease Research Center at Duke University) were used. $\mathrm{AD}$ and control cases were matched for age and PMD as closely as possible (Table 1). Conventional autopsy tissue: mean age $\mathrm{AD}=78.1$ years, control $=75$ years; mean $\mathrm{PMD} \mathrm{AD}=3.5 \mathrm{hr}$, control $=6.25 \mathrm{hr}$. Rapid autopsy tissue: mean age $\mathrm{AD}=81.5$ years, control $=66.5$ years; mean PMD AD $=55 \mathrm{~min}$, control $=54 \mathrm{~min}$. $\mathrm{AD}$ and control cases were processed in parallel for all staining procedures to ensure the inclusion of a positive control.

Immunocytochemistry. Tissue was processed as described previously (Cummings et al., 1992; Anderson et al., 1994). Tris-saline refers to $0.1 \mathrm{M}$ Tris-saline buffer, $\mathrm{pH} 7.5$; Tris-A refers to $0.1 \%$ Triton X-100 in Trissaline; Tris-B refers to $0.1 \%$ Triton $\mathrm{X}-100$ plus $2.0 \% \mathrm{BSA} / 3$ drops per 10 $\mathrm{ml}$ of normal serum to the species in which the secondary antibody was raised. All washes and incubations were at room temperature $\left(25^{\circ} \mathrm{C}\right)$. Briefly, tissue was treated with $3 \%$ hydrogen peroxide $10 \%$ methanol in Tris-saline for $30 \mathrm{~min}$, followed by Tris-A and Tris-B for $15 \mathrm{~min}$ each. Tissue was then incubated with primary antibody in Tris-B overnight, washed in Tris-A and Tris-B, and incubated for $1 \mathrm{hr}$ with biotinylated horse anti-mouse $\mathrm{IgG}$ or goat anti-rabbit IgG secondary (ABC Elite immunoperoxidase kit, Vector Laboratories, Burlingame, CA). Tissue was washed again in Tris-A and Tris-B, incubated $1 \mathrm{hr}$ with avidin-biotin complex (Vector), washed several times in Tris-saline, and reacted for
5-7 min with diaminobenzidine (DAB; Vector). Optimal antibody dilutions were determined by titration of stock antibody concentrations in serial dilutions and are detailed below. All antibodies showed an approximately linear decrease in staining with increasing dilution. Incubations in the absence of either primary or secondary antibody were negative.

Antibodies. Well characterized, commercially available antibodies were used. The Oricogene Sciences c-Jun antibody (PC06, 1:25; Uniondale, NY) is an affinity-purified rabbit polyclonal antibody raised against amino acids 209-225 of c-Jun. This antibody recognizes mouse, rat, and human c-Jun; although this antibody is c-Jun-specific by Western blotling (Jensen et al., 1991), the manufacturer reports that it can exhibit some cross-reactivity with Jun B and Jun D. The Santa Cruz c-Jun antibody (SC-45, 1:125-1:4000; Santa Cruz, CA) is an aflinity-purified rabbit polyclonal antibody raised against a peptide corresponding to residues $91-105$ of the protein encoded by mouse $c$-jun. This antibody recognizes chicken, mouse, rat, and human c-Jun with no detectable cross-reactivity for other Jun proteins. The Jun B antibody (SC-46, 1:125-1:4000; Santa Cruz) is an affinity-purified rabbit polyclonal antibody raised against a peptide corresponding to residues $45-61$ of the protein encoded by mouse jun $B$. This antibody recognizes mouse, rat, and human Jun B, with no detectablc cross-reactivity for other Jun proteins. The Jun D antibody (SC-74, 1:125-1:4000; Santa Cruz) is a rabbit polyclonal antibody raised against a peptide corresponding to residues 329-341 of the protein encoded by mouse jun $D$. This antibody recognizes mouse, rat, and human Jun D, with no detectable cross-reactivity for other Jun proteins.

Immunoreactivity for several of the antibodies tested in this study was fixation-dependent. The distribution and prevalence of $\mathrm{c}$-Jun immunoreactivity detected using the Santa Cruz SC-45 antibody in paraformaldehydefixed tissue was comparable with that observed with the Oncogene Sciences PC06 antibody. However, SC-45 produced much less robust labeling than PC06 in the formalin-fixed tissue required to visualize TdT labeling. At dilutions of SC 45 sufficient to visualize c-Jun immunoreactivity in formalinfixed tissue, background staining prohibited double-labeling. As a result of these parameters, we used the Oncogene Sciences PC06 c-Jun antibody in all TdT double-labeling experiments.

To verify the specificity of PC06 for c-Jun in human postmortem tissue, we also examined the prevalence and distribution of immunoreactivity for Jun B and Jun D in AD brain. To ensure that a lack of immunoreactivity did not reflect a fixation effect, we conducted immunostaining on both formalin- and paraformaldehyde-fixed tissue at a wide range of dilutions above and below the manufacturer's recommendations. Although exhibiting some fixation dependence, Jun B- and Jun D-specific antibodies revealed only scattered, low levels of immunoreactivity principally confined to the white matter (Jun B) or no immunoreactivity (Jun D) in the hippocampus/entorhinal cortex. We also examined immunoreactivity for Jun B and Jun D in the hypothalamus as a positive control. Several nuclei in the rat hypothalamus have been reported to exhibit constitutive ex-

Table 1. Control and AD case information, and relative TdT labeling in the entorhinal cortex (EC) and cerebellum (CBL) of the cases examined

Case information

\begin{tabular}{|c|c|c|c|c|c|c|c|}
\hline Case \# & Diagnosis & Sex & Age & PMD & Cause of death & $\mathrm{EC}$ & $\mathrm{CBL}$ \\
\hline $1-93$ & $\mathrm{C}$ & $\mathrm{M}$ & 86 & $4.5 \mathrm{hr}$ & cardiopulmonary arrest & + & \\
\hline $9-93$ & $\mathrm{C}$ & $\mathrm{F}$ & 76 & $4.5 \mathrm{hr}$ & myocardial infarction & + & \\
\hline $16-93$ & $\mathrm{C}$ & $F$ & 64 & $8 \mathrm{hr}$ & myocardial infarction & + & \\
\hline $49-93$ & $\mathrm{C}$ & M & 74 & $8 \mathrm{hr}$ & cardiac arrest & ++ & \\
\hline 418 & $\mathrm{C}^{*}$ & M & 74 & $70 \mathrm{~min}$ & $\mathrm{n} / \mathrm{a}$ & + & \\
\hline 159 & $\mathrm{C}^{*}$ & $\mathrm{~F}$ & 59 & $40 \mathrm{~min}$ & lung cancer & $+1-$ & \\
\hline $10-93$ & $\mathrm{AD}$ & $\mathrm{F}$ & 73 & $0.5 \mathrm{hr}$ & pncumonia & +++ & $+/-$ \\
\hline $24-93$ & $\mathrm{AD}$ & $\mathrm{F}$ & 78 & $5.5 \mathrm{hr}$ & cardiac arrest & +++ & + \\
\hline $26-93$ & $\mathrm{AD}$ & M & 77 & $6.5 \mathrm{hr}$ & cardiac arrest & +++ & ++++ \\
\hline $27-93$ & $\mathrm{AD}$ & M & 71 & $4 \mathrm{hr}$ & pneumonia, lung cancer & +++ & $\mathrm{n} / \mathrm{a}$ \\
\hline $28-93$ & $\mathrm{AD}$ & M & 81 & $3.5 \mathrm{hr}$ & cardiac arrest & ++++ & + \\
\hline $31-93$ & $\mathrm{AD}$ & M & 79 & $2 \mathrm{hr}$ & respiratory failure, renal failure & +++ & $+1-$ \\
\hline $45-93$ & $\mathrm{AD}$ & $\mathrm{F}$ & 88 & $2.5 \mathrm{hr}$ & respiratory failure & + & $\mathrm{n} / \mathrm{a}$ \\
\hline 123 & $\mathrm{AD}^{*}$ & $\mathrm{~F}$ & 84 & $48 \min$ & $\mathrm{n} / \mathrm{a}$ & +++ & $\mathrm{n} / \mathrm{a}$ \\
\hline 188 & $\mathrm{AD}^{*}$ & M & 79 & $60 \mathrm{~min}$ & $\mathrm{n} / \mathrm{a}$ & +++ & $\mathrm{n} / \mathrm{a}$ \\
\hline
\end{tabular}

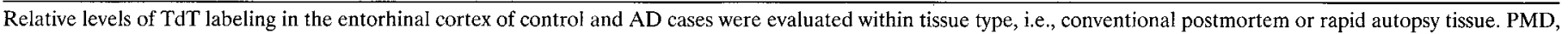
Postmortem delay; ${ }^{*}$, rapid autopsy tissue; n/a, not available. 
pression of Jun D and to upregulate expression of Jun B with mild types of stress, such as immobilization (Honkaniemi et al., 1992; Umemoto et al., 1994). Immunoreactivity for both Jun B and Jun D was present in human hypothalamic nuclei, most prominently in the paraventricular nucleus. Dilutions of the Jun B and Jun D antibodies that revealed Jun B and Jun D immunoreactivity in the hypothalamus did not reveal cellular staining in scetions of cntorhinal cortcx/hippocampus. Finally, preabsorption with c-Jun peptide (Oncogene Sciences, $40-400 \mu \mathrm{g} / \mathrm{ml}$ ) significantly reduced or abolished PC06 immunostaining (Anderson et al., 1994) These data confirm the specificity of the immunoreactivity detected with the Oncogene Sciences PC06 c-Jun antibody. As a result, in this paper we refer to immunoreactivity detected with this antibody as c-Jun immunoreactivity.

TdT 3'-OH DNA strand break labeling. TdT labeling was based on the techniques of Gavrieli et al. (1992) and Gorczya et al. (1993). ApopTag peroxidase kits (Oncor, Gaithersburg, MD) were used to detect digoxigenin-nucleotide residues added by TdT to the $3^{\prime}-\mathrm{OH}$ termini of DN $\Lambda$ strand breaks. Briefly, tissue sections were incubated in equilibration buffer $(30 \mathrm{~min})$ followed by TdT enzyme and digoxigenin-deoxyuridine triphosphate (dUTP) reaction buffer $(60 \mathrm{~min})$ at $37^{\circ} \mathrm{C}$. Sections were then washed for $30 \mathrm{~min}$ at $37^{\circ} \mathrm{C}$, followed by incubation in antidigoxigenin antibody conjugated with peroxidase or fluorescein for 30 min at room temperature. Digoxigenin-dUTP-peroxidase complex was visualized by reacting with $\mathrm{DAB}$ (Vector) to generate a brown reaction product. Negative controls were performed by substituting distilled water for TdT enzyme in the preparation of working solution and were negative.

In the case of double-labeling experiments, potential cross-reactivity between $D A B$ reactions was blocked by driving the first reaction to completion in the absence of substrate using $3 \%$ hydrogen peroxide $10 \%$ methanol in Tris-saline for $30 \mathrm{~min}$ after the first round of staining was complete and before beginning the second. As described previously (Su et al., 1994), brown DAB (generally TdT) was visualized in the first round of staining followed by SG DAB (blue reaction product, generally c-Jun) in the second, because SG DAB is somewhat water-soluble and fades in PBS. Additionally, sections were neutral red- or Nissl-counterstained.

$c-J u n / T d T$ colocalization. Colocalization of c-Jun and TdT was quantitatively evaluated in both conventional and rapid autopsy $\mathrm{AD}$ cases double-labeled for these markers. Tissue included in these data was processed in parallel for both c-Jun immunocytochemistry and TdT labeling, and neutral red-counterstained. Using a $10 \times 10$ reticule and a $20 \times$ objective, the total number of c-Jun-positive cells and TdT-positive cells and the number of TdT-positive/c-Jun-positive cells were counted in five fields of entorhinal cortex/case. Final magnification was $200 \times$. Counts were centered in layer III. These results are expressed as percentage of TdT-positive cells exhibiting c-Jun immunoreactivity and percentage of c-Jun-immunoreactive cells exhibiting TdT labeling.

Genomic DNA isolation and gel electrophoresis. The most common method used to identify DNA fragmentation in association with apoptosis is ethidium bromide staining after gel electrophoresis of genomic DNA isolates; however, ethidium bromide staining is dependent on the length of the DNA fragment. Thus, visualization of oligonucleosome-length fragments requires large amounts of DNA undergoing apoptotic cleavage. In contrast, the signal generated by labeling genomic DNA isolates with ${ }^{32} \mathrm{P}$-labeled nucleotides is independent of fragment length and produces a considerably greater sensitivity for the detection of degraded DNA. Genomic DNA was isolated using QIAamp reagents and protocols (QIAamp tissue kit, Qiagen, Chatsworth, CA). Genomic DNA from 50 $\mathrm{mg}$ of frozen unfixed tissue was end-labeled using the Klenow fragment of DNA polymerase 1, with minor modifications to the technique described by Rosl (1992). Briefly, DNA was treated with $1 \mathrm{U} / \mu \mathrm{g}$ Klenow polymerase ( $5000 \mathrm{U} / \mathrm{ml}$, Promega, Madison, WI) and $0.5 \mu \mathrm{Ci} / \mu \mathrm{g}\left[{ }^{32} \mathrm{P}\right]$ deoxycytidine triphosphate (dCTP; $3000 \mathrm{Ci} / \mathrm{mmol}$, Amersham, Arlington Heights, IL) in reaction buffer consisting of $50 \mathrm{~mm}$ Tris- $\mathrm{HCl}, \mathrm{pH} 7.2,10 \mathrm{mM} \mathrm{MgSO}_{4}$, and $1 \mathrm{mM}$ dithiothreitol. The reaction was allowed to proceed for $10 \mathrm{~min}$ at room temperature and terminated with $10 \mathrm{~mm}$ EDTA. The presence of only a single nucleotide prevents the $3^{\prime}-5^{\prime}$ exonuclease activity of Klenow polymerase from producing a nick translation effect; thus, these results reflect only the labeling of $3^{\prime}$ DNA ends. To remove unincorporated dCTP, labeled DNA was subjected to two rounds of precipitation $(1 \mathrm{hr}$ each) with $2.5 \mathrm{M}$ ammonium acetate and 2.5 volumes of ethanol in the presence of $50 \mu \mathrm{M}$ tRNA carrier, followed by centrifugation for $30 \mathrm{~min}$ at $4^{\circ} \mathrm{C}$. Labeled DNA was washed with $70 \%$ ethanol, resuspended in $20 \mu \mathrm{l}$ of $10 \mathrm{mM}$ Tris-EDTA, and either run immediately on a $1.8 \%$ agarose gel or stored at $-20^{\circ} \mathrm{C}$ until use. After ethidium bromide staining of the gel and photography of $100 \mathrm{bp}$ standards (Gibco, Grand Island, NY) included for later reference, the gel was placed on four sheets of $3 \mathrm{~mm}$ Whatman filter paper (Bio-Rad, Richmond, CA), dried under vacuum in a Bio-Rad slab gel drier for $2 \mathrm{hr}$ (no heat), sealed in plastic, and exposed to autoradiography film for $6-24 \mathrm{hr}$ (Hyperfilm- $\beta$ max or Hyperfilm-MP, Amersham).

\section{RESULTS}

\section{TdT labeling}

Apoptosis is defined based on strict morphological criteria, including shrinkage of the cytoplasm, condensation of the chromatin into dense granular masses, margination of dense masses of aggregated chromatin into large caps or crescents at the periphery of the nuclear membrane, early dissolution of the nucleolus, membrane blebbing, and the formation of apoptotic bodies (Wyllie et al., 1980). Apoptosis is also characterized by the cleavage of DNA into oligonucleosome-length fragments detectable by gel electrophoresis and the lack of an inflammatory response. Conversely, necrosis involves the swelling of the nucleus and cytoplasm, condensation of the chromatin into small loose aggregates, margination of these aggregates to the periphery of the nuclear membrane, and late dissolution of the nucleolus (Wyllie et al., 1980). Necrosis also involves degradation of DNA into randomlength fragments and the generation of an inflammatory response. Because DNA degradation occurs in both apoptosis and necrosis, both apoptotic and necrotic DNA strand breaks can be labeled by enzymes such as TdT. Moreover, it is increasingly apparent that apoptosis and necrosis are not mutually exclusive processes and that there may be a continuum between these pathways (Lennon et al., 1991; Kunimoto, 1994). Thus, it is important to evaluate TdT labeling in the context of the morphological characteristics of apoptosis detectable at the light microscopy level, and to be cautious in drawing conclusions regarding the mechanism of cell death in postmortem tissue labeled using such techniques (Cotman and Anderson, 1995).

In the present study, we observed TdT labeling to be fixationdependent. Neither control nor AD tissue fixed in 4\% Sorensen's buffered paraformaldehyde exhibited TdT labeling (data not shown). In contrast, robust labeling was apparent in postmortem AD tissue fixed in $10 \%$ formalin (Figs. 1-5). In general, we ohserved low levels of TdT labeling in control cases, but frequent TdT-positive nuclei in brain tissue from $\mathrm{AD}$ cases. Many of these labeled cells exhibited an apoptotic-like morphological distribution of DNA strand breaks, including granulated and marginated patterns of intense TdT labeling, shrunken, irregular cellular shape, and the presence of what appeared to be apoptotic bodies (Fig. 1). TdT labeling occurred in distinct cells, not in clumped groups of cells, as would be expected in the case of necrosis, where cell lysis and inflammation have resulted in the involvement of clusters of nearby cells. TdT-labeled nuclei were not found in association with gross histological evidence suggestive of necrosis. Importantly, TdT labeling was examined in both conventional postmortem (average PMD $=4.5 \mathrm{hr}$ ) and rapid autopsy tissue (average $\mathrm{PMD}=55 \mathrm{~min}$ ). Importantly, at least one rapid autopsy case was administered oxygen to minimize complications due to hypoxia. TdT labeling exhibited a similar pattern in control versus AD cases for both conventional and rapid autopsy tissue, although in accordance with tissue quality, the quality of labeling was better in the conventional postmortem tissue (see Table 1 for a summary of relative TdT labeling for the tissue examined).

Neuropsychological assessments within 18 months of death were available for five of the seven conventional autopsy AD cases in this study. In the majority of these $(4 / 5)$, neuropsychological 


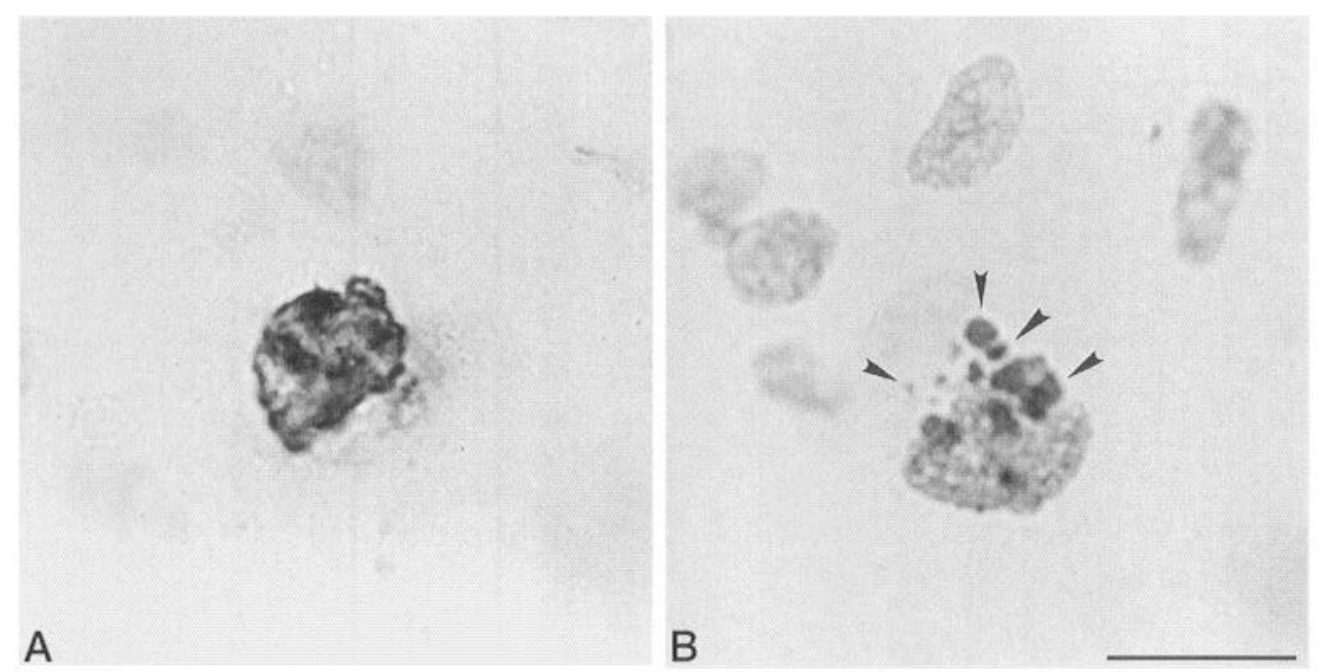

Figure 1. High-power illustration of the morphological distribution of TdT labeling. $A$, Note the cell shrinkage and clumping of the TdT-labeled chromatin. $B$, Note the formation and apparent blebbing of apoptotic bodies from the cell (arrowheads). Scale bar, $10 \mu \mathrm{m}$. status had been assessed within 12 months of death. A large degree of TdT labeling was observed in four of five of these cases, all of which also had mini mental status exam (MMSE) scores of $15 / 30$ or greater, indicating a mild-to-moderate degree of dementia. In contrast, the single conventional autopsy case exhibiting low levels of TdT labeling (45-93) had an MMSE of 1/30, indicating a severe degree of dementia (Table 1). Such an observation would be expected if the majority of cell loss is actively occurring relatively early in the disease. It may be possible to evaluate this hypothesis in future correlative studies.

\section{Colocalization of TdT-positive cells with c-Jun immunoreactivity}

All of the AD cases examined in this study exhibited an increase in immunoreactivity for c-Jun compared with controls (Anderson et al., 1994). As described in Materials and Methods, immunoreactivity for both c-Jun and Jun-related protein antibodies was also tested. Immunocytochemistry for Jun B revealed only scattered immunopositive cells, principally in the white matter; the morphology of these cells suggested that they were astrocytic in type. No labeling for Jun D was detected (data not shown). The lack of neuronal Jun B and Jun D immunoreactivity in AD tissue is in agreement with our previous findings in vitro (Anderson et al., 1994), and suggests that increases in c-Jun in AD reflect the activation of a specific IEG response.

Cells double-labeled for TdT and c-Jun were distributed throughout the neuronal layers of the hippocampus and entorhinal cortex, and exhibited several staining morphologies. In some cases, c-Jun immunoreactivity was restricted to the nucleus; in this event, it was often possible to observe TdT-labeled chromatin that had aggregated into dense masses within the nucleus, or granular aggregates of TdT-labeled chromatin that had marginated to the periphery of the nuclear membrane (Fig. $2 A, B$ ). c-Jun immunoreactivity also was noted in some cells with lighter, more diffuse patterns of TdT labeling (Fig. 2C). In other cases, a TdT-positive nucleus with a c-Jun-positive apical dendrite was observed (Fig. $2 D$ ). We reported a similar characteristic for c-Jun immunoreactivity in AD previously (Anderson et al., 1994). TdT-positive nuclei exhibiting multiple c-Jun-immunoreactive processes also were observed (Fig. 2E,F). In all cases, c-Jun immunoreactivity in neuronal processes appeared to be present proximally rather than distally to the cell body. As described previously, microglia could be seen responding to some nuclei exhibiting DNA damage by neutral red or Nissl counterstaining (Su et al., 1994). However, most TdT-positive nuclei were neutral red-negative (Fig. 2A-E). Furthermore, c-Jun was not seen in association with neutral red-positive nuclei proximal to TdT-labeled cells, suggesting that c-Jun immunoreactivity in association with TdT labeling did not reflect IEG expression in glia responding to injured cells.

Counts of c-Jun-positive and TdT-positive cells in the entorhinal cortex of double-labeled AD tissue revealed that $56.3 \%$ of c-Jun-positive cells were TdT-positive and that $43.2 \%$ of TdTpositive cells were c-Jun-positive (Fig. 3C). As is apparent in Figure 2, double-labeled cells generally appeared to be neuronal in type; however, it is possible that these counts could reflect some glial labeling for c-Jun and/or TdT. Finally, as noted earlier, it may not be possible to distinguish apoptosis and necrosis using TdT labeling in all instances. Although examples of classical apoptotic morphology in AD brain using TdT (e.g., Fig. 1) are abundant, it is unclear whether light, agranular TdT labeling (e.g., Fig. 2C) represents an early stage of apoptosis, necrosis, or the detection of DNA damage that has not led to either of these mechanisms as yet. The presence of TdT labeling in combination with another marker induced during neuronal apoptosis, c-Jun, supports an apoptotic mechanism of cell death in at least some neurons in the AD brain.

Plaques and neurofibrillary tangles were present in two of the conventional postmortem control cases, although the overall numbers of these lesions did not meet CERAD criteria for diagnosis of AD. Examination of sections from these cases double-labeled for c-Jun and TdT revealed higher levels of both c-Jun immunoreactivity and TdT labeling in some areas than observed in other control cases. These data suggest that these cases may reflect an early or transitional stage in $\mathrm{AD}$, and that significant damage in association with apoptosis may be initiated before the development of sufficient levels of pathology to meet formal neuropathological criteria for AD. Figure 3 shows double-labeling for c-Jun and TdT in a control $(A)$, a transitional $(B)$, and an AD case $(C)$. Note the high degree of correspondence between intensely TdTpositive cells and c-Jun in both the transitional and the AD case.

\section{TdT labeling in relation to brain area}

If the large increase in TdT labeling in AD compared with control brain is related to disease pathology and not a nonspecific artifact, TdT labeling would be predicted to be found in brain areas typically exhibiting AD pathology and neuronal cell loss, such as entorhinal cortex, but not in areas in which such pathology is generally absent, such as cerebellum. TdT labeling was absent or 

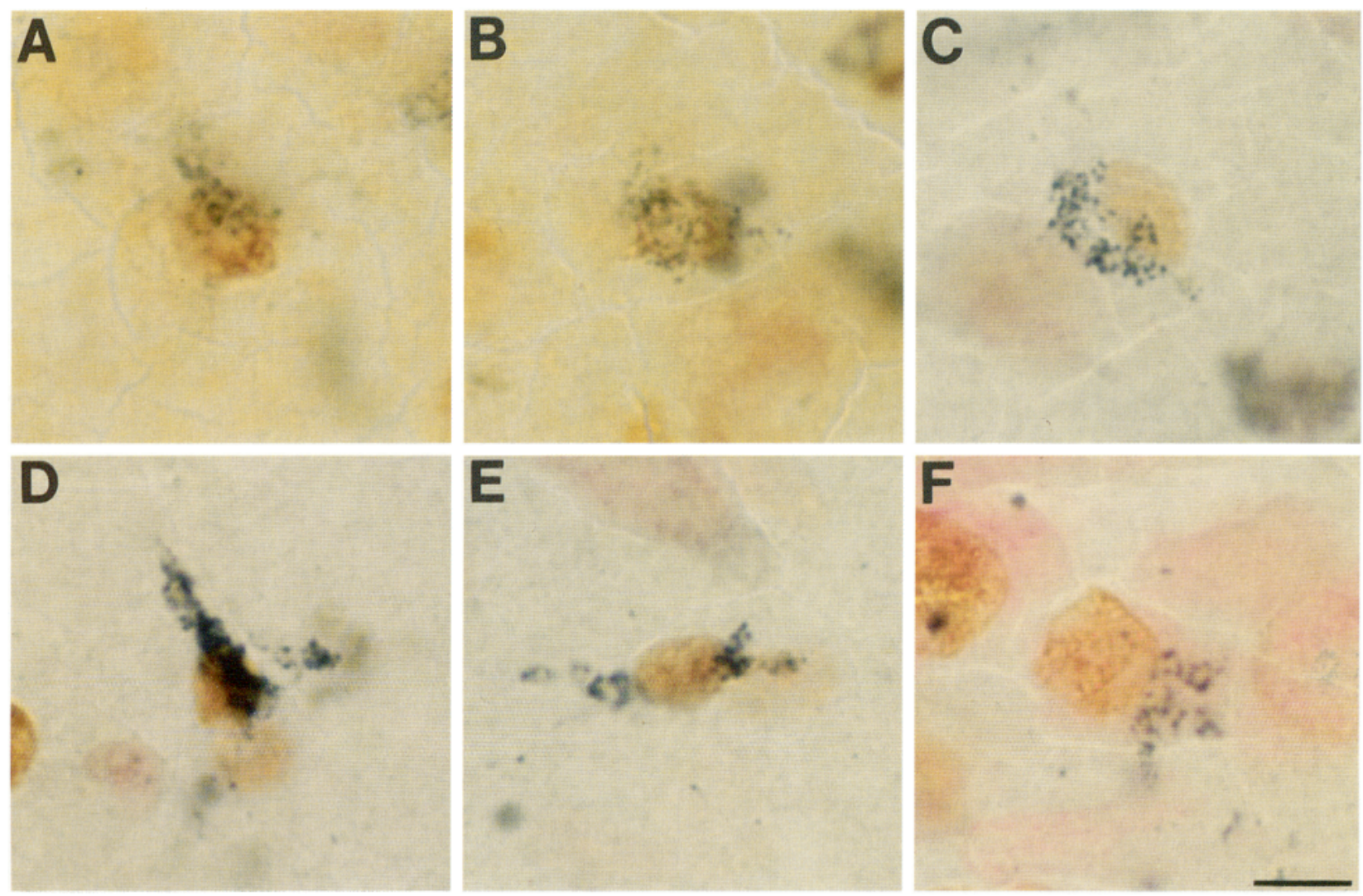

Figure 2. Colocalization of c-Jun immunoreactivity (blue) and TdT labeling (brown) in $\mathrm{AD}$. All sections have been counterstained for neutral red. A, B, Note the intense, punctate, and clumped appearance of the labeled chromatin, and the margination of labeled chromatin to the periphery of the cell body. $C$, c-Jun immunoreactivity in a nucleus with lighter TdT labeling. $D$, Intense c-Jun immunoreactivity in the cell body and apical dendrite of a TdT-positive neuron. $E, F$, c-Jun immunoreactivity in the processes of TdT-labeled neurons. Note the lack of neutral red staining in TdT-positive nuclei in $A-E$. Scale bar, $5 \mu \mathrm{m}$.
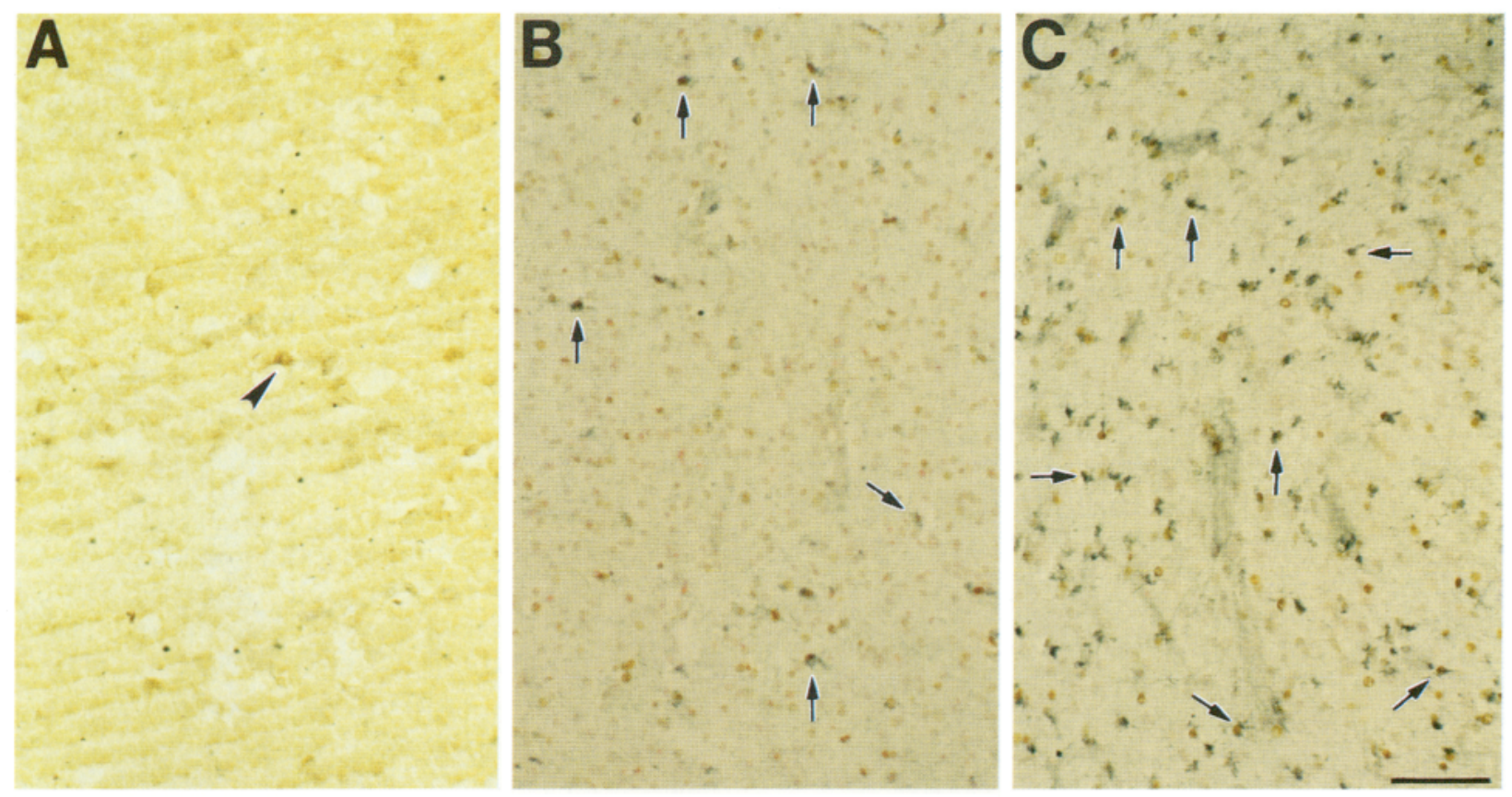

Figure 3. c-Jun and TdT labeling in the entorhinal cortex of a control $(A)$, a transitional $(B)$, and an AD case $(C)$. $B$ and $C$ are counterstained with neutral red. TdT-positive nuclei are occasionally present in $A$ (arrowhead). Note the progressive increase in both c-Jun immunoreactivity and TdT labeling in $B$ and $C$. Additionally, this figure provides a low-power view of the degree of colocalization between TdT and c-Jun in AD $(C)$; in this context, note that a large proportion of the intensely TdT-positive cells in both $B$ and $C$ is also c-Jun-positive (arrows). $50 \mu \mathrm{m}$ sections. Scale bar, $100 \mu \mathrm{m}$. 


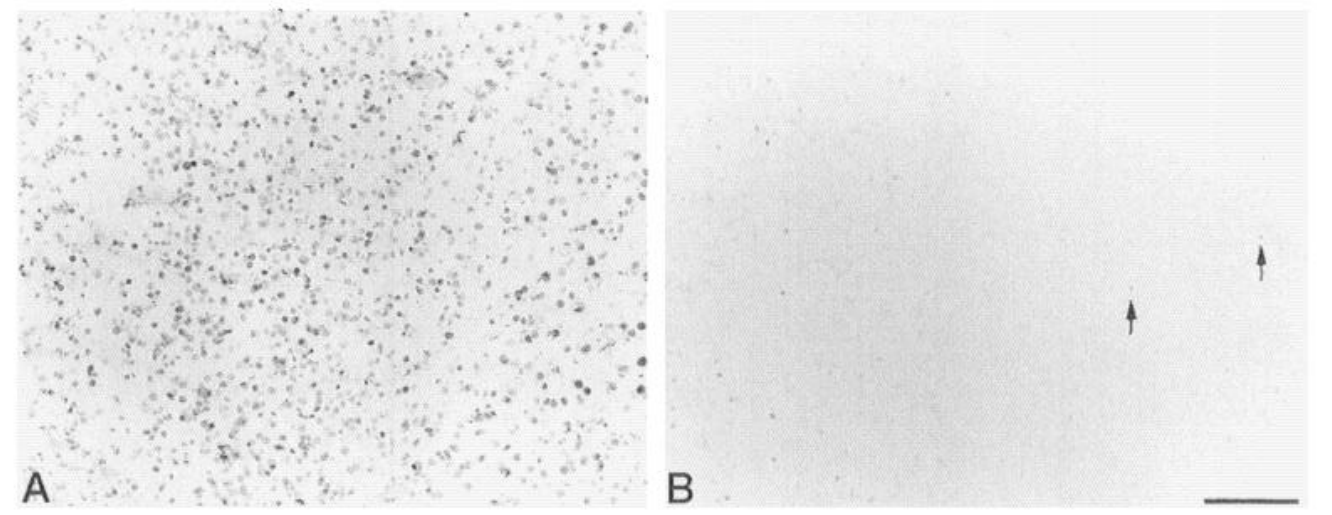

Figure 4. Relationship of TdT labeling to brain area. Entorhinal cortex $(A)$ and cerebellum $(B)$ of the same $\mathrm{AD}$ case. Arrows indicate labeled cells in the deep granular layer of the cerebellum. $50 \mu \mathrm{M}$ sections. Scale bar, $100 \mu \mathrm{m}$. present at comparatively very low levels in the cerebellum versus entorhinal cortex of four of five AD cases examined (Table 1, Fig. 4). Labeling in these cases consisted of scattered TdT-positive cells in the molecular layer, and occasional TdT-positive Purkinje cells and cells in the granular layer. Some variability across areas of the same section was noted. In the remaining cases (26-93), extremely high levels of TdT labeling were found in the cerebellum.

\section{Effect of PMD on TdT labeling}

As noted above, conventional and rapid autopsy tissue exhibited similar patterns of TdT labeling. We extended this observation by conducting a postmortem curve on an $\mathrm{AD}$ case with an initial PMD of $3.5 \mathrm{hr}$. A slice of frontal cortex was maintained in a humidified chamber at room temperature for $24 \mathrm{hr}$. Blocks of this cortical slice were removed and fixed in $10 \%$ neutral buffered formalin at PMDs of 3.5, 4.5, 6.5, 8.5, 12.5, and $24 \mathrm{hr}$. Tissue from each of these PMD time points was cut and processed for TdT labeling as described in Materials and Methods.

TdT labeling did not exhibit clear, consistent changes with PMDs of up to $6.5 \mathrm{hr}$ (Fig. 5). At a PMD of $8.5 \mathrm{hr}$, increases in TdT labeling in the glia limitans and layers I-III of cortex had begun to appear; changes in TdT labeling in the deeper cortical layers were less apparent. These changes also could be found in some areas of the sections processed for TdT at a PMD of $6.5 \mathrm{hr}$ but, overall, changes in TdT labeling at this time point were within the limits of variability for the tissue at earlier PMDs. At $12.5 \mathrm{hr}$ PMD, an increase in neuropil staining was observed in some areas, and diffuse patches of neuropil labeling had began to appear. All cortical layers exhibited an increase in the number of TdT-positive cells relative to earlier time points, although many of these cells were lightly rather than intensely TdT-positive.

At $24 \mathrm{hr}$ PMD, a large increase in the number of TdT-positive cells and dense process staining was evident. Numerous large and small accumulations of TdT labeling were present in the neuropil. These areas could reflect TdT labeling attributable to cell lysis, caused by either postmortem necrosis or secondary necrosis in apoptotic cells. At this time point, the quality of cellular TdT labeling appeared more homogeneous and agranular or diffuse than that observed earlier, although what we have termed apoptotic-like nuclei based on morphological characteristics were still present. Many of the labeled pyramidal-type cells in layers III and $\mathrm{V}$ appeared to be increased in size. Interestingly, the diffuse/ homogeneously labeled nuclei in layer I first observed at $8.5 \mathrm{hr}$ PMD appeared more granular and classically apoptotic in morphology at $24 \mathrm{hr}$ PMD, perhaps suggesting the progression of apoptotic processes postmortem. Furthermore, this observation suggests that diffuse TdT labeling is an early stage in the progression to apoptotic-like morphology in some cells.

\section{Gel electrophoresis for DNA fragmentation in AD and controls}

In an attempt to definitively identify the mechanism of DNA damage and cell loss in $\mathrm{AD}$, we examined genomic DNA from four $\mathrm{AD}$ and four control cases for the presence of either an apoptotic ladder of oligonucleosome-length DNA fragments or a smear of randomly cleaved necrotic DNA fragments. Genomic DNA was isolated from entorhinal cortex of two AD (26-93, 28-93) and two control cases (9-93, 16-93), and from the frontal cortex of two AD $(123,188)$ and two control cases $(159,418)$, and analyzed for DNA fragmentation using ${ }^{32} \mathrm{P}$ end-labeling with Klenow polymerase (DNA polymerase I) to visualize DNA strand breaks as described in Materials and Methods. The genomic DNA from seven of eight samples appeared intact; no evidence for either apoptosis or necrosis was detected using this technique (Fig. 6). DNA degradation, seen as a shift in the principal genomic DNA band on agarose gel electrophoresis and a trailing or partial smear of the DNA, was apparent in one AD case, 26-93 (data not shown). This case also was the only AD case to exhibit TdT labeling in the cerebellum.

\section{DISCUSSION}

A principal goal of this study was to examine the colocalization of immunoreactivity for c-Jun with TdT-labeled nuclei in AD brain. The colocalization of c-Jun immunoreactivity with TdT labeling supports the hypothesis that c-Jun may participate in an apoptosis-related gene program. If this hypothesis is true, there are at least two factors likely to contribute to the lack of complete colocalization between c-Jun-positive and TdT-positive cells. First, c-Jun is a transcriptional regulatory protein that forms homodimers with itself or heterodimers with other IEG proteins (Morgan and Curran, 1991). Thus, c-Jun may regulate different processes in different cells/cell types, depending on the other IEG transcription factors available. This point is particularly relevant in regard to the ratio of c-Jun-positive cells that also were TdTpositive, because this c-Jun antibody labels both neurons and astrocytes in AD brain (Anderson et al., 1994). As described in Results, however, cells double-labeled for c-Jun and TdT in the present study were morphologically neuronal in type. Because counts of all c-Jun-positive cells include both neuronal and glial labeling, these counts provide only a conservative estimate of the degree of colocalization between c-Jun and TdT in the neuronal population. Second, the lack of detectable evidence for either apoptosis or necrosis by gel electrophoresis suggests that TdT 


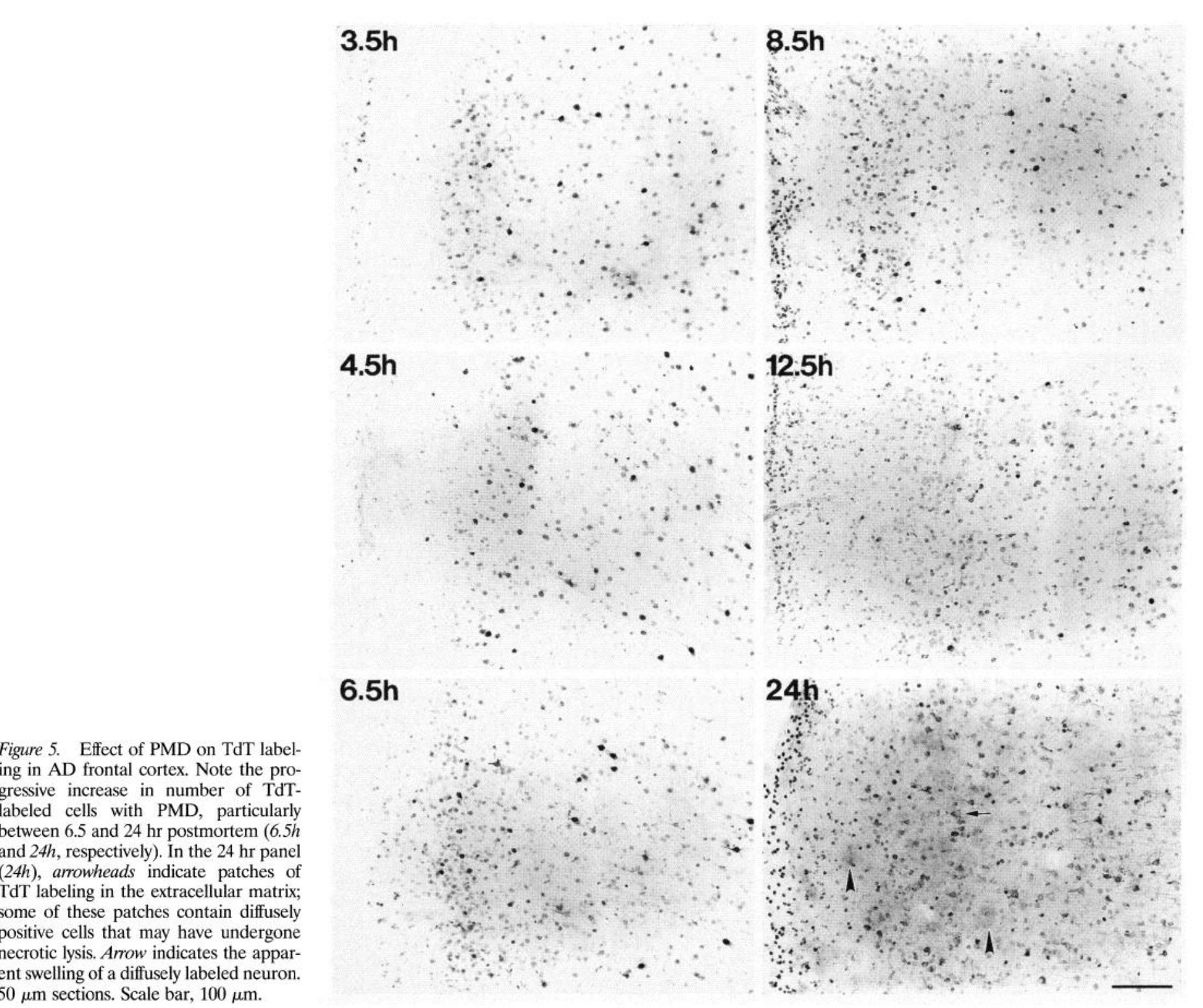

Figure 5. Effect of PMD on TdT labeling in $\mathrm{AD}$ frontal cortex. Note the probetween 6.5 and $24 \mathrm{hr}$ postmortem $(6.5 \mathrm{~h}$ and $24 \mathrm{~h}$, respectively). In the $24 \mathrm{hr}$ panel (24h), arrowheads indicate patches of TdT labeling in the extracellular matrix; some of these patches contain diffusely positive cells that may have undergone ent swelling of a diffusely labeled neuron. $50 \mu \mathrm{m}$ sections. Scale bar, $100 \mu \mathrm{m}$. labeling cannot be equated with cell death per se (see below); therefore, a complete correspondence between c-Jun and TdT would not be expected if c-Jun does in fact play a role in cell death. However, two additional possibilities must also be considered: c-Jun expression may be associated with a specific stage or aspect of DNA damage and/or cell death or, alternatively, there may be two or more separate pathways of DNA damage and/or cell death, only one of which involves c-Jun.

We have described previously an atypical pattern of immunoreactivity for c-Jun in human postmortem tissue in which immunoreactivity was observed not only in the nucleus, but also in the cytoplasm and processes of the cell. We again observed this cellular distribution of c-Jun immunoreactivity. This pattern of immunoreactivity is unlikely to be attributable to postmortem effects, because similar findings also were observed in the rapid autopsy tissue processed for this study. An alternative possibility is that the shrinkage and loss of cytoplasm associated with apoptosis, and/or a breakdown in normal cellular compartmentalization in injured cells, could result in the partial transfer of proteins expressed at high levels in the nucleus and cytoplasm into proximal cellular areas. Interestingly, a similar distribution of the IEG
c-Fos has been described both in fibroblasts induced to undergo apoptosis in vitro (Smeyne et al., 1993) and in neurons vulnerable to cell death after kainic acid-induced seizures in vivo (Kasof et al., 1995).

Many investigators have reported that paraformaldehyde fixation is adequate for the detection of DNA fragmentation in rat brain (Nitatori et al., 1995; Portera-Cailliau et al., 1995); however, to our knowledge, TdT labeling has not been reported in paraformaldehyde-fixed human brain. The lack of TdT labeling in 4\% paraformaldehyde-fixed tissue in the present study may be related to a loss of DNA. Although aldehyde fixatives are effective at cross-linking proteins, they do not immobilize nucleic acids, and DNA has been shown to diffuse out of archived tissue stored in fixative over time (Jackson et al., 1991). In contrast, precipitating fixatives such as methanol do immobilize nucleic acids to some extent. The presence of alcohol derivatives (10-15\% methyl alcohol) in commercially available formalin but not in commercially available paraformaldehyde may influence the retention of nucleic acids in postmortem human brain. Alternatively, formalin, being a stronger fixative than paraformaldehyde, may increase the retention of nucleic acids in archived tissue. This issue may be 


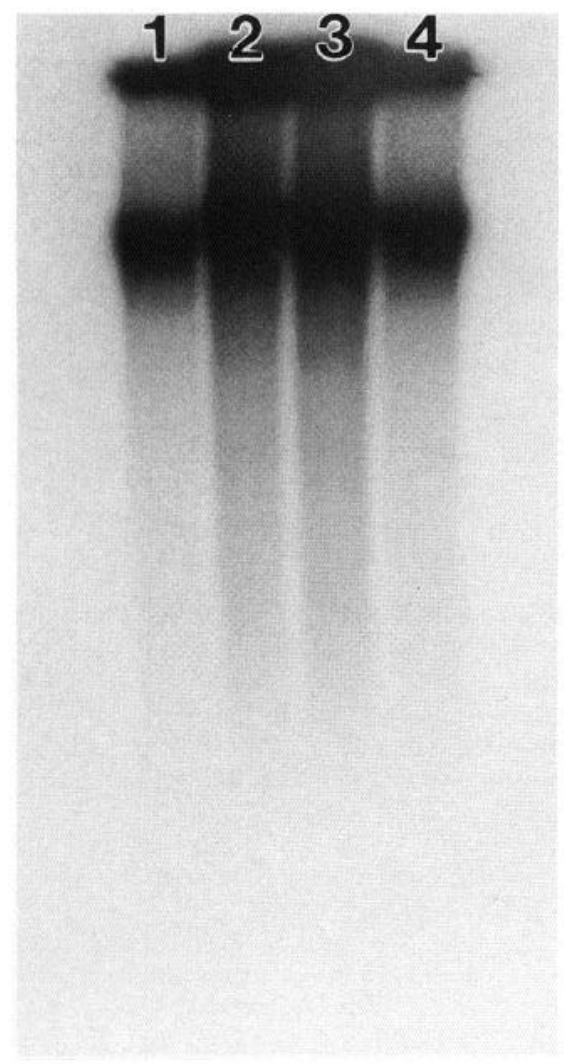

Figure 6. Representative autoradiograph of ${ }^{32} \mathrm{P}$ end-labeled genomic DNA from two control cases (lanes 1 and 2) and two AD cases (lanes 3 and 4$)$.

compounded by relatively slow fixative penetration in postmortem human tissue compared with perfused rodent tissue.

We addressed the issue of potential TdT labeling artifacts by examining two factors: the relationship of TdT labeling to brain area and the effect of PMD on TdT labeling. Our findings for TdT labeling in the cerebellum and entorhinal cortex correspond with previous results regarding ultrastructural neuronal injury and the formation of AD pathology in these areas (Yamazaki et al., 1992; Li et al., 1994), supporting the hypothesis that TdT labeling reflects $\mathrm{AD}$-related pathological processes and neuronal loss. It has recently been reported that PMD does not affect TdT labeling (Lassmann et al., 1995; Portera-Cailliau et al., 1995). Although TdT labeling in relation to PMD was qualitatively compared across the cases used in these studies and in a short (6 hr) PMD curve conducted on rat brain, our data provide a more thorough examination of this issue and demonstrate that PMD does in fact affect TdT labeling in human brain. Quantitative biochemical data on DNA strand breaks in human cerebral cortex support this observation (Mullaart et al., 1990). Importantly, a somewhat different result might be observed in control tissue; if cells in the AD brain are at an increased level of stress or risk, it may be that they are more likely to exhibit an increase in terminal DNA strand breaks with increasing PMD, or exhibit such an increase more rapidly.

Two other groups have recently examined DNA strand break labeling in AD tissue. Lassman et al. (1995) used a TdT-labeling technique similar to that used in our studies; however, these authors state that the majority of labeled cells did not exhibit morphological characteristics suggestive of apoptosis. Rather, it was suggested that the majority of labeled cells either may have been necrotic in type or may represent an atypical form of apoptosis. Because all of the AD cases used in that study had PMDs of $10 \mathrm{hr}$ or more, our findings suggest that PMD could have significantly influenced the results. Migheli et al. (1994) describe negative results for DNA strand break labeling in AD tissue using Klenow polymerase; however, the fixation for the AD tissue used in that study is unclear. In contrast to this result and in support of our findings, a greater than twofold increase in DNA strand breaks has been reported in $\mathrm{AD}$ versus control cerebral cortex using biochemical techniques (Mullaart et al., 1990). Furthermore, DNA strand break labeling techniques using Klenow polymerase, as in Migheli et al. (1994), are less sensitive than techniques using TdT (Gold et al., 1994).

Gel electrophoresis of ${ }^{32} \mathrm{P}$ end-labeled genomic DNA is an extremely sensitive technique for the detection of DNA degradation, which has been used successfully both in vitro and in vivo (Rosl, 1992; Tilly and Hsueh, 1993; Beilharz et al., 1995; PorteraCailliau et al., 1995) (A. Anderson, unpublished observations). However, the lack of evidence for DNA fragmentation with this technique does not preclude a role for apoptosis in AD. Recent attempts to definitively identify apoptosis in Huntington's disease brain using end-labeling combined with gel electrophoresis were also unsuccessful (Portera-Cailliau et al., 1995). Although gel electrophoresis revealed no detectable DNA degradation in the majority of cases in the present study, the partial degradation of ${ }^{32} \mathrm{P}$ end-labeled DNA in entorhinal cortex combined with intense TdT labeling in the cerebellum of one of the cases examined (26-93) suggests that factors such as agonal state must be considered. Because premortem conditions (e.g., ischemia) could result in necrosis, apoptosis, or a combination of these events (Dragunow et al., 1994; Nitatori et al., 1995), such conditions clearly can be expected to contribute to variability among cases.

As is apparent from Figures 3 and 4, a large number of TdTlabeled nuclei in the entorhinal cortex/hippocampal formation of AD cases were observed in this study. Although DNA strand breaks detected with TdT certainly reflect an increase in DNA damage in $\mathrm{AD}$ compared with control brain, and although many of these cells exhibit clear morphological characteristics of apoptosis, it is unlikely that all of these cells are undergoing cell death by either apoptosis or necrosis during the disease stage captured at autopsy. TdT labeling in some of these cells could represent an active process of DNA damage-DNA repair in cells at risk or an accumulation of cells undergoing apoptosis but not being cleared effectively by normal brain phagocytic processes.

The lack of evidence for either apoptotic or necrotic cell death in $\mathrm{AD}$ brain by gel electrophoresis strongly supports the former possibility. The accumulation of DNA damage as the result of deficient DNA repair has previously been suggested to play a role in neurodegeneration in AD (Boerrigter et al., 1992; Mazzarello et al., 1992). Alternatively, there could be an acceleration of DNA damage in $\mathrm{AD}$ and a corresponding initiation of compensatory mechanisms. In either case, the detection of DNA damage by TdT labeling may reflect one of the earliest markers of neuronal abnormality in AD brain and, correspondingly, an increased vulnerability of neuronal cells to insult. Interestingly, immunoreactivity for both the cell death inhibitor Bcl-2 (Satou et al., 1995) and the DNA repair enzyme Ref-1 (A. Anderson, J. Su, and C. Cotman, unpublished observations) is elevated in AD neurons. Furthermore, there is a strong colocalization between $\mathrm{Bcl}-2$ and $\mathrm{TdT}$ labeling in $\mathrm{AD}$ brain (Su et al., in press). These proteins could be components of a dynamic and extended competition between cell death processes and compensatory responses in the 
AD brain. Conversely, reports on AD tissue have estimated cell loss in layer 2 of the entorhinal cortex as high as $87 \%$ compared with aged normal control subjects (Lippa et al., 1992); thus, the possibility that the high number of TdT-labeled cells observed could be consistent with a slow or deficient clearance process cannot be excluded.

Although DNA damage detected by TdT labeling was more prevalent than might have been suspected previously, it is clear that there is a large increase in the extent of DNA damage in AD compared with control brain, and that many of the cells exhibiting DNA damage also exhibit apoptotic morphological features. In addition, we observed a pattern of TdT labeling across brain areas that would be predicted if DNA damage were associated with AD pathology and cell loss. However, our data also suggest that TdT labeling detects a large number of DNA-damaged neurons, and thus cannot simply be equated with cell death. Finally, we report that TdT labeling and c-Jun immunoreactivity exhibit a high, but not complete, degree of colocalization in AD brain. In accordance with the hypothesis that, in many neurons, TdT labeling reflects DNA damage rather than cell death, a complete correspondence between TdT labeling and c-Jun immunoreactivity would not be expected if c-Jun is in fact involved in cell death. In this context, c-Jun immunoreactivity, in combination with TdT labeling, may provide a more definitive marker for neurons that are undergoing a cell death program. These data support the hypothesis that c-Jun may participate in regulating early events associated with DNA damage and/or apoptosis in AD.

\section{REFERENCES}

Anderson AJ, Cummings BJ, Colman CW (1994) Increased immunoreactivity for Jun- and Fos-related proteins in Alzheimer's disease: association with pathology. Exp Neurol 125:286-295.

Anderson AJ, Pike CJ, Cotman CW (1995) Differential induction of IEGs in response to $A \beta$ peptides in cultured neurons: association between c-Jun immunoreactivity and $A \beta$-mediated apoptosis. J Neurochem 65:1487-1498.

Beilharz EJ, Williams CE, Dragunow M, Sirimanne ES, Gluckman PD (1995) Mechanisms of delayed cell death following hypoxic-ischemic injury in the immature rat: evidence for apoptosis during selective neuronal loss. Mol Brain Res 29:1-14.

Bhalla K, Tang C, Ibrado A, Grant S, Tourkina E, Holladay C, Hughes M, Mahoney M, Huang Y (1992) Granulocyte-macrophage colony stimulating factor/interleukin-3 fusion protein ( $\mathrm{pIXY} 321$ ) enhances high dose Ara-C-induced programmed cell death or apoptosis in human myeloid leukemia cells. Blood 80:2883-2890.

Boerrigter ME, Wei JY, Vijg J (1992) DNA repair and Alzheimer's disease. J Gerontol 47:B177-B184.

Brach MA, Herrmann F, Kufe DW (1992) Activation of the AP-1 transcription factor by arabinofuranosylcytosine in myeloid leukemia cells. Blood 79:728-734.

Bullock G, Tang C, Tourkina E, Ibrado AM, Lutzky J, Huang Y, Mahoney ME, Bhalla K (1993) Effect of combined treatment with interleukin-3 and interleukin-6 on 4-hydroperoxycyclo-phosphamide-induced programmed cell death or apoptosis in human myeloid leukemia cells. Exp Hematol 21:1640-1647.

Bursch W, Oberhammer F, Schulte-Hermann R (1992) Cell death by apoptosis and its protective role against disease. Trends Pharmacol Sci 13:245-251.

Colotta F, Polentarutti N, Sironi M, Mantovani A (1992) Expression and involvement of $\mathrm{c}$-fos and c-jun proto-oncogenes in programmed cell death induced by growth factor deprivation in lymphoid cell lines. J Biol Chem 267:18278-18283.

Cotman CW, Anderson AJ (1995) A potential role for apoptosis in neurodegeneration and Alzheimer's disease. Mol Neurobiol 10:1-19.

Cummings BJ, Su JH, Geddes JW, Van Nostrand W, Wagner S, Cunningham D, Cotman CW (1992) Aggregation of the amyloid precursor protein (APP) within degenerating neurons and dystrophic neurites in Alzheimer's disease. Neuroscience 48:763-777.
Dragunow M, Beilharz E, Sirimanne E, Lawlor P, Williams C, Bravo R, Gluckman P (1994) Immediate-early gene protein expression in neurons undergoing delayed death, but not necrosis, following hypoxicischacmic injury to the young rat brain. Mol Brain Res 25:19-33.

Duke RC, Chervenak R, Cohen JJ (1983) Endogenous endonucleaseinduced DNA fragmentation: an early event in cell-mediated cytolysis. Proc Natl Acad Sci USA 80:6361-6365.

Estus S, Zaks WJ, Freeman RS, Gruda M, Bravo R, Johnson EM (1994) Altered gene expression in neurons during programmed cell death: identification of $\mathrm{c}$-jun as necessary for neuronal apoptosis. $\mathrm{J}$ Cell Biol 126:1717-1727.

Forloni G, Chiesa R, Smiroldo S, Verga L, Salmona M, Tagliavini F, Angeretti N (1993) Apoptosis mediated neurotoxicity induced by chronic application of beta anyloid fragment 25-35. NeuroReport 4:523-526.

Gavrieli Y, Sherman Y, Ben SS (1992) Identification of programmed cell death in situ via specific labeling of nuclear DNA fragmentation. J Cell Biol 119:493-501.

Gold R, Schmied M, Giegerich G, Breitschopf H, Hartung HP, Toyka KV, Lassmann II (1994) Differentiation between cellular apoptosis and necrosis by the combined use of in situ tailing and nick translation techniques. Lab Invest 71:219-225.

Gorczya W, Gong J, Darzynkiewicz Z (1993) Detection of DNA strand breaks in individual apoptotic cells by the in situ terminal deoxynucleotidyl transferase and nick translation assays. Cancer Res 53:1945-1951.

Ham J, Babij C, Whitfield J, Pfarr CM, Lallemand D, Yaniv M, Rubin LL (1995) A c-Jun dominant negative mutant protects sympathetic neurons against programmed cell death. Neuron 14:927-939.

Honkaniemi J, Kainu T, Ceccatelli S, Rechardt L, Hokfelt T, Pelto HM (1992) Fos and jun in rat central amygdaloid nucleus and paraventricular nucleus after stress. NeuroReport 3:849-852.

Jackson DP, Hayden JD, Quirke P (1991) Extraction of nucleic acid from fresh and archival material. In: PCR: a practical approach (McPherson MJ, Quirke P, Taylor GR, eds), pp 29-50. New York: Oxford UP.

Jensen DE, Frankis RJ, Sando JJ (1991) Defective induction of Jun and Fos-related proteins in phorbol ester-resistant ELA mouse thymoma cells. Oncogene 6:1219-1225.

Kasof GM, Mandelzys A, Maika SD, Hammer RE, Curran T, Morgan JI (1995) Kainic acid-induced neuronal death is associated with DNA damage and a unique immediate early gene response in c-fos-lacZ transgenic rats. J Neurosci 15:4238-4249.

Kunimoto M (1994) Methylmercury induces apoptosis of rat cerebellar neurons in primary culture. Biochem Biophys Res Commun $204: 310-317$.

Lassmann H, Bancher C, Breitschopf $\mathrm{H}$, Wegiel J, Bobinski M, Jellinger $\mathrm{K}$, Wisniewski H (1995) Cell death in Alzheimer's disease evaluated by DNA fragmentation in situ. Acta Neuropathol (Berl) 89:35-41.

Lennon SV, Martin SJ, Cotter TG (1991) Dose-dependent induction of apoptosis in human tumour cell lines by widely diverging stimuli. Cell Prolif 24:203-214.

Li YT, Woodruff PD, Trojanowski JQ (1994) Amyloid plaques in cerebellar cortex and the integrity of Purkinje cell dendrites. Neurobiol Aging 15:1-9.

Lippa CF, Hamos JE, Pulaski SD, DeGennaro LJ, Drachman DA (1992) Alzheimer's disease and aging: effects on perforant pathway perikarya and synapses. Neurobiol Aging 13:405-411.

Loo DT, Copani AG, Pike CJ, Whittemore ER, Walencewicz. A., Cotman CW (1993) Apoptosis is induced by beta-amyloid in cultured central nervous system neurons. Proc Natl Acad Sci USA 90:7951-7955.

Marti A, Jehn B, Costello E, Keon N, Ke G, Martin F, Jaggi R (1994) Protein kinase A and AP-1 (c-Fos/JunD) are induced during apoptosis of mouse mammary epithelial cells. Oncogene 9:1213-1223.

Mazzarello P, Poloni M, Spadari S, Focher F (1992) DNA repair mechanisms in neurological diseases: facts and hypotheses. J Neurol Sci 112:4-14.

Migheli A, Cavalla P, Marino S, Schiffer D (1994) A study of apoptosis in normal and pathologic nervous tissue after in situ end-labeling of DNA strand breaks. J Neuropathol Exp Neurol 53:606-616.

Mirra SS, Heyman A, McKeel D, Sumi SM, Crain BJ, Brounlee LM, Vogel FS, Hughes JP, VanBelle G, Berg L (1991) The consortium to establish a registry for Alzheimer's disease (CERAD). II. Standardization of the neuropathological assessment of Alzheimer's disease. Neurology $41: 479-486$. 
Morgan JI, Curran T (1991) Stimulus-transcription coupling in the nervous system: involvement of the inducible proto-oncogenes fos and jun. Annu Rev Neurosci 14:421-451.

Mullaart E, Bocrrigter METI, Ravid R, Swaab DF, Vijg J (1990) Increased levels of DNA breaks in cerebral cortex of Alzheimer's disease patients. Neurobiol Aging 11:169-173.

Nitatori T, Sato N, Waguri S, Karasawa Y, Araki H, Shibanai K, Kominami E, Uchiyama Y (1995) Delayed neuronal death in the CA1 pyramidal cell layer of the gerbil hippocampus following transient ischemia is apoptosis. J Neurosci 15:1001-1011.

Portera-Cailliau C, Herdeen JC, Price DL, Koliatsos VE (1995) Evidence for apoptotic cell death in Huntington's disease and excitotoxic animal models. J Neurosci 15:3775-3787.

Rosl F (1992) A simple and rapid method for detection of apoptosis in human cells. Nucleic Acids Res 20:5243.

Rubin E, Kharbanda S, Gunji H, Weichelbaum R, Kufe D (1992) cisDiaminedichloroplatinum(II) induces c-jun expression in human myeloid leukemia cells: potential involvement of a protein kinase C-dependent signaling pathway, Cancer Res 52:878-882.

Satou T, Cummings BJ, Cotman CW (1995) Immunoreactivity for Bcl-2 protein within neurons in the Alzheimer's disease brain increases with disease severity. Brain Res 697:35-43.

Sikora E, Grassilli E, Bellesia E, Troiano L, Franceschi C (1993) Studies of the relationship between cell proliferation and cell death. III. AP-1 DNA-binding activity during concanavalin A-induced proliferation or dexamethasone-induced apoptosis of rat thymocytes. Biochem Biophys Res Commun 192:386-391.
Smeyne RJ, Vendrell M, Hayward M, Baker SJ, Miao GG, Schilling K, Robertson LM, Curran T, Morgan JI (1993) Continuous c-fos expression precedes programmed cell death in vivo. Nature 363:166-169.

Su JH, Anderson AJ, Cummings BJ, Cotman CW (1994) Immunohistochemical evidence for DNA fragmentation in neurons in the $\mathrm{AD}$ brain. NeuroReport 5:2529-2533.

Su JH, Satou T, Anderson AJ, Cotman CW (1996) Upregulation of Bcl-2 is associated with neuronal DNA damage in Alzheimer's disease. NeuroReport, in press.

Tepper CG, Studzinski GP (1992) Teniposide induces nuclear but not mitochondrial DNA degradation. Cancer Res 52:3384-3390.

Tilly JL, Hsueh AJ (1993) Microscale autoradiographic method for the qualitative and quantitative analysis of apoptotic DNA fragmentation. J Cell Physiol 154:519-526.

Umemoto S, Kawai Y, Senba E (1994) Differential regulation of IEGs in the rat PVH in single and repeated stress models. NeuroReport 6:201-204.

Wyllie AH, Kerr JFR, Currie AR (1980) Cell death: the significance of apoptosis. Int Rev Cytol 68:251-306.

Wyllie AH, Morris RG, Smith AL, Dunlop D (1984) Chromatin cleavage in apoptosis: association with condensed chromatin morphology and dependence on macromolecular synthesis. J Pathol 142:67-77.

Yamazaki T, Yamaguchi $H$, Nakazato $Y$, Ishiguro K, Kawarabayashi $T$, Hirai S (1992) Ultrastructural characterization of cerebellar diffuse plaques in Alzheimer's disease. J Neuropathol Exp Neurol 51:281-286.

Zakeri ZF, Quaglino D, Latham T, Lockshin RA (1993) Delayed internucleosomal DNA fragmentation in programmed cell death. FASEB J $7: 470-478$. 